
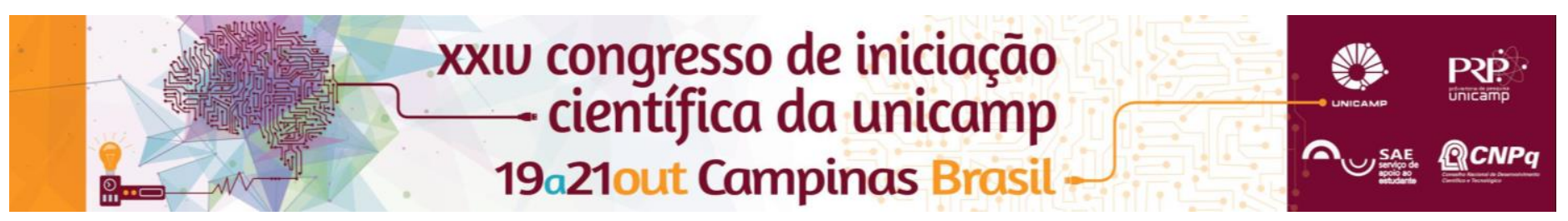

\title{
Caracterização de Fibras Microestruturadas Poliméricas.
}

\author{
Luiz E. da Silva*, Thiago H. R. Marques, Cristiano M. B. Cordeiro.
}

\section{Resumo}

Neste trabalho apresentamos os resultados preliminares na caracterização de fibras ópticas poliméricas microestruturadas (mPOFs) fabricadas em nosso grupo no Instituto de Física da Unicamp. O objetivo consiste em avaliar a qualidade das fibras produzidas, verificando a influência do processo de fabricação na estrutura final, bem como o guiamento e perda óptica das fibras.

\section{Palavras-chave:}

Fibras ópticas, fibras ópticas microestruturadas, polímero.

\section{Introdução}

Nosso foco aqui será a avaliação da qualidade das fibras poliméricas (tipicamente de PMMA) fabricadas em nosso laboratório [1]. Com isso podemos verificar se, ao final do processo, a fibra mantém as propriedades desejadas. Verificamos, assim, o guiamento através da perda óptica e distribuição modal.

\section{Resultados e Discussão}

Grande parte do interesse em mPOFs reside em sua aplicação como sensor óptico. Além de possibilitar designs inovadores outra vantagem das fibras poliméricas em comparação com as fibras tradicionais de sílica é a grande abertura numérica, o que facilita 0 acoplamento de luz no núcleo da fibra.

O contraste entre os índices de refração da casca e do núcleo está intimamente ligado à distribuição de energia eletromagnética que se propaga na fibra, ou seja, aos modos ópticos. A função da estrutura ao redor do núcleo é justamente criar uma região com índice de refração menor para que a luz fique confinada no núcleo.

$\mathrm{Na}$ figura 1, apresentamos uma mPOF com arranjo hexagonal de buracos. Primeiro vemos o desenho da preforma (versão macroscópica da fibra antes do puxamento) (fig.1a) e, em seguida, a foto da fibra produzida (fig.1b). Usando uma CCD (charge-coupled device) verificamos o modo fundamental se propagando (fig.1c). Essa fibra apresenta uma perda óptica (medida preliminar) da ordem de $\mathrm{dB} / \mathrm{cm}$.

Também estudamos o guiamento de uma fibra planar. Essa, ao contrário da anterior, possui um design inovador que justifica o uso de polímeros. Sua morfologia faz com que ela se curve em uma só direção. Uma provável aplicação futura será como sensor de curvatura.
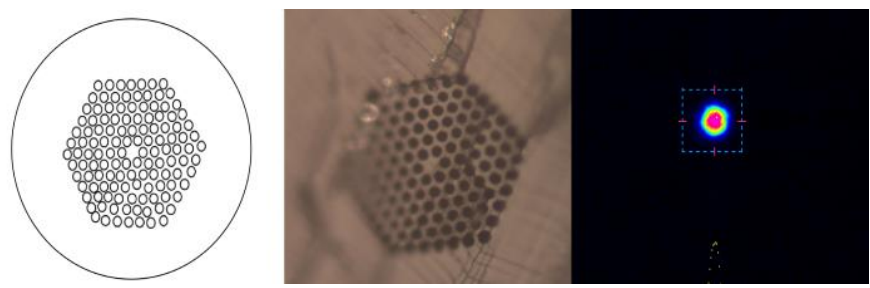

Figura 1 - mPOF com perfil hexagonal, a) esquema da preforma, b) microscopia óptica da fibra produzida, c) imagem do modo guiado.
Outra fibra estudada foi a fibra Kandinsky - nomeada em homenagem ao pintor de origem russa (fig.2a). Nesta estrutura, as finas paredes de polímero fazem com que ocorra um efeito de interferência da luz. Com isso, quando fazemos passar pela fibra um espectro largo, apenas alguns comprimentos de onda se propagam em cada buraco, graças ao efeito de antirressonância.
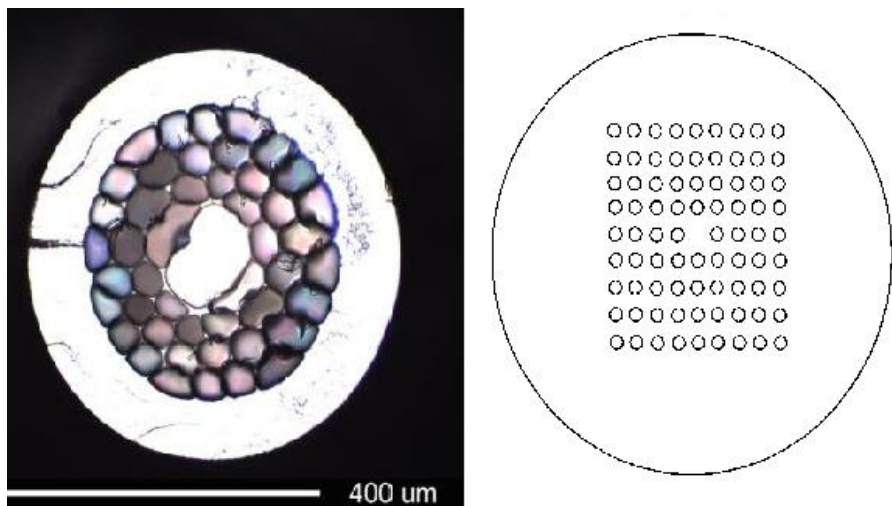

Figura 2 - a) fibra Kandinsky e, b) projeto de fibra com perfil quadrado

Uma fibra com um arranjo retangular de buracos está sendo desenvolvida de forma a produzir um guia de onda com núcleo quadrado. A fig. $2 \mathrm{~b}$ mostra o esquema da fibra que será fabricada no decorrer deste projeto.

\section{Conclusões}

Pudemos neste trabalho iniciar a familiarização com a área de pesquisa de fibras microestruturadas caracterizando 0 guiamento de algumas estruturas fabricadas no grupo e iniciando o projeto de uma nova fibra.

\section{Agradecimentos}

Agradecemos ao SAE (Serviço de Apoio ao Estudante) e à Unicamp pelo suporte.

1 Marques, T. H. R.; Salvador, A. J.; Cordeiro, C. M. B.; Fabrication of Microestructured Polymer Optical Fibers, XXIV Congresso de Iniciação Científica da Unicamp, 2016 